\title{
Some Strains in Search of a Genus-Corynebacterium, Mycobacterium, Nocardia or What?
}

\author{
By RUTH E. GORDON \\ Institute of Microbiology, Rutgers, The State University of New Jersey, \\ New Brunswick, New Jersey, U.S.A.
}

(Received 26 August 1965)

\begin{abstract}
SUMMARY
In a continued search for a more suitable generic location for the species tentatively designated Mycobacterium rhodochrous (Overbeck) Gordon \& Mihm, strains of some species of Corynebacterium, both animal and plant pathogens, were found to have the same morphology and the same, or nearly the same, physiological properties as strains of the species provisionally labelled $\boldsymbol{M}$. rhodochrous. Additional tests and observations applied to the strains of the species $M$. rhodochrous resulted in a pattern of approximately 30 different characteristics which distinguished the species. Among the newly studied properties was the ability to utilize glucose oxidatively. Because strains of the type species of the genus Corynebacterium ferment glucose, the assignment of the glucose-oxidizing strains tentatively named $\boldsymbol{M}$. rhodochrous to the genus Corynebacterium is not proposed.
\end{abstract}

\section{INTRODUCTION}

During the study of the mycobacteria, nocardias, and streptomycetes, a group of strains believed to represent a definite species was tentatively designated Mycobacterium rhodochrous (Overbeck) Gordon \& Mihm (1959). Strains of this one species were received from different investigators as representatives of species of the following genera: Bacillus, Bacterium, Erythrobacillus, Micrococcus, Mycobacterium, Nocardia, Proactinomyces, Rhodococcus, Serratia, and later Jensenia (Gordon \& Mihm, 1961). The number of generic names clearly reflects the uncertainty of the generic position of the species.

Because the colonial morphology of these strains resembled that of the mycobacteria more closely than the colonial morphology of the nocardias, as typified by Nocardia asteroides, and because some strains of Mycobacterium rhodochrous when first isolated from soil were known to be as acid-fast as, for example, strains of $M$. phlei, the species was provisionally assigned to the genus Mycobacterium. The oldest name borne by these strains was Rhodococcus rhodochrous. This species was described by Overbeck (1891), and his account did not disprove the authenticity of our strains labelled $M$. rhodochrous. In accordance with the rule of priority of the International Code of Nomenclature of Bacteria and Viruses (1958), we called the species $M$. rhodochrous, but warned that examination of more strains might necessitate a change in both generic and specific names.

In a continued attempt to determine the generic location of this species, strains of Mycobacterium rhodochrous were compared with strains of some species of 
Corynebacterium. The results of this comparison are presented here in the hope that they may be useful in the recognition of strains of the species and in its generic assignment.

\section{METHODS}

The strains compared included those listed in Tables 1 and 2 , those listed by Gordon \& Mihm (1959, 1961), and 25 strains of Mycobacterium fortuitum received as Mycobacterium spp. from laboratories of human or veterinary medicine. In addition to those used by Gordon \& Mihm (1959), the tests and observations described below were applied to the strains. Unless other temperatures are specified, all cultures were incubated at $28^{\circ}$.

Microscopic examination. Cultures grown on Waksman's 'yeast dextrose agar' (yeast extract, 10 g.; glucose, 10 g.; agar, 15 g.; distilled water, $1000 \mathrm{ml}$.; pH 7·0: Waksman, 1950) were stained by the Gram method after $18 \mathrm{hr}$ and after 5 days of incubation.

Deamination of phenylalanine. Cultures were streaked on slants of the following composition: yeast extract, 3 g.; DL-phenylalanine, 2 g.; $\mathrm{Na}_{2} \mathrm{HPO}_{4}, \mathrm{l}$ g.; $\mathrm{NaCl}, 5$ g.; agar, 12 g.; distilled water, $1000 \mathrm{ml}$. (Ewing, Davis \& Reavis, 1957). After 14 days, four or five drops of $10 \%(\mathrm{w} / \mathrm{v})$ of $\mathrm{FeCl}_{3}$ were pipetted over the growth on the slants. The development of a green colour in the agar demonstrated the formation of phenylpyruvic acid from the phenylalanine.

Decomposition of xanthine. Xanthine $(0.4 \mathrm{~g}$.) was suspended in $100 \mathrm{ml}$. nutrient agar (peptone, 5 g.; beef extract, 3 g.; agar, 15 g.; distilled water, $1000 \mathrm{ml}$.; pH 7·0); the suspension was then autoclaved, cooled to $47^{\circ}$, mixed thoroughly, and poured into sterile Petri dishes (20 ml. per plate). Care was taken to distribute the insoluble crystals of xanthine evenly throughout the agar. Each culture was streaked once across a plate and checked at 14 and 21 days for the disappearance of the crystals underneath and around the growth.

Fermentation or oxidation of glucose. Both the Hugh \& Leifson (1953) test and a modification of the test were used to determine whether the cultures utilized glucose fermentatively or oxidatively. The basal medium of Hugh \& Leifson contained: peptone, 2 g.; NaCl, 5 g.; $\mathrm{K}_{2} \mathrm{HPO}_{4}$, $0.3 \mathrm{~g}$.; agar, $3 \mathrm{~g}$; $1 \%$ (w/v) aqueous solution

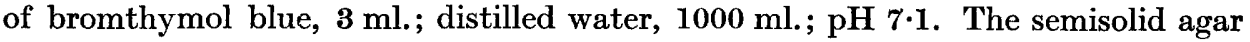
was tubed $(7.5 \mathrm{ml}$. per tube, $16 \mathrm{~mm}$. in diameter), autoclaved, and quickly cooled. Before the agar solidified, $0.5 \mathrm{ml}$. of $15 \%(\mathrm{w} / \mathrm{v})$ aqueous solution of glucose, also sterilized by autoclaving, was added to each tube. As soon as the agar became firm, duplicate tubes were inoculated by stabbing from a 3-day-old culture in glucose broth; one tube was sealed with vaspar (paraffin, $60 \%$ (w/w); vaseline, $40 \%(w / w))$. The vaspar seal occasionally pulled away from the inside of the tube during the first $24 \mathrm{hr}$ of incubation, and the culture was resealed by heating the glass around the vaspar in a small flame. The cultures were observed at 7 and 28 days. A culture that was growing and producing the acid colour of the indicator in both the aerobic and anaerobic tubes was recorded as fermenting glucose; a culture that was growing in both tubes but forming the acid colour of the indicator in only the aerobic tube was recorded as oxidizing glucose.

The ability of each strain to produce acid from a series of carbohydrates, including glucose, was determined by growing the cultures aerobically on slants of the in- 
organic nitrogen agar of Ayers, Rupp \& Johnson (1919) containing $1 \%(w / v)$ of each carbohydrate (Gordon \& Mihm, 1959). The cultures were also tested for the fermentation of glucose in the inorganic nitrogen agar $\left(\left(\mathrm{NH}_{4}\right)_{2} \mathrm{HPO}_{4}, 1 \mathrm{~g}\right.$.; KCl, 0.2 g.; $\mathrm{MgSO}_{4} .7 \mathrm{H}_{2} \mathrm{O}, 0.2 \mathrm{~g}$.; agar, $3 \mathrm{~g}$.; distilled water, $1000 \mathrm{ml}$; $0.04 \%$ solution of bromcresol purple, $15 \mathrm{ml}$.). Glucose was added to this medium in the same way as to the Hugh \& Leifson medium; the cultures were inoculated, sealed with a vaspar seal, and observed at 7 and 28 days.

Hydrolysis of hippurate. The modification of Ayers \& Rupp's test (1922), described by Baird-Parker (1963), was used. The cultures were inoculated into hippurate broth (tryptone, $10 \mathrm{~g}$.; beef extract, $3 \mathrm{~g}$.; yeast extract, $1 \mathrm{~g}$.; glucose, 1 g.; $\mathrm{Na}_{2} \mathrm{HPO}_{4}, 5$ g.; $\mathrm{Na}$ hippurate, 10 g.; distilled water, 1000 ml.). After 6 weeks of incubation, the cultures were examined for benzoic acid by mixing $1 \mathrm{ml}$. of the culture, as free of clumps of growth as possible, with $1.5 \mathrm{ml}$. of $50 \%(\mathrm{v} / \mathrm{v}) \mathrm{H}_{2} \mathrm{SO}_{4}$. The appearance of crystals in the acid mixture after $4 \mathrm{hr}$ at room temperature was accepted as evidence of the hydrolysis of hippurate.

Sensitivity to penicillin. A tube containing $20 \mathrm{ml}$. of 'yeast dextrose agar' was inoculated with one or two loopsful, depending on the turbidity, of a 14- to 28-dayold culture in glucose broth. The agar was carefully mixed and poured into a sterile Petri dish. After the agar solidified, a penicillin disc (Bacto-sensitivity disc, 10 units) was placed on the agar with sterile forceps. Because the agar was sometimes thin at the centre of the plate, the disc was placed approximately $2 \mathrm{~cm}$. away from the centre. Plates were incubated and observed at 3, 5, and 7 days for a zone of inhibition around the disc. Some cultures were so sensitive to penicillin they did not grow on the plate. In such instances, the cultures used as inoculum were tested for viability.

\section{RESULTS}

\section{Mycobacterium rhodochrous (Overbeck) Gordon \& Mihm}

Recently examined strains found to possess the morphology and pattern of reactions of the species tentatively named Mycobacterium rhodochrous are listed in Table 1. Representatives of nomenclatural species not previously encountered were strains received as Corynebacterium fascians (Tilford, 1936) Dowson (1941), $C$. rubrum Crowle (1962), M. hyalinum Söhngen (1913), and Rhodococcus cinnabareus (Flügge, 1886) Winslow \& Rogers (1906). The strains representing C. fascians, C. rubrum, and $\boldsymbol{M}$. hyalinum included nomenclatural-type strains, or strains distributed by the author of the species. These strains were believed to agree with their original descriptions and were accepted as authentic. Strain 806 was one of two strains received bearing the name Rhodococcus cinnabareus; the other strain, labelled Micrococcus cinnabareus (ATcC 11890), is listed in Table 2. Flügge (1886) characterized $\boldsymbol{M}$. cinnabareus as a large, spherical micrococcus, often situated in twos, threes, or fours, that grew very slowly. As this portion of Flügge's meagre description did not seem to apply to strain 806 and ATCC 11890, these strains were not accepted as authentic.

Two strains (28 and 584) received as Mycobacterium lacticola differed markedly from two strains ( 8150 and N 8153) from the National Collection of Type Cultures, previously recognized as strains of $M$. smegmatis (Gordon \& Smith, 1953). As strains $\mathrm{N} 8150$ and $\mathrm{N} 8153$ were not at variance with the original account of $M$. 
lacticola (Lehmann \& Neumann, 1899), they were accepted as authentic, and $\boldsymbol{M}$. lacticola was assigned to the synonymy of $M$. smegmatis. Because Lehmann \& Neumann's description of $\boldsymbol{M}$. lacticola seemed to apply more closely to strains of $\boldsymbol{M}$. smegmatis than to strains 28 and 584, these two strains were regarded as misnamed.

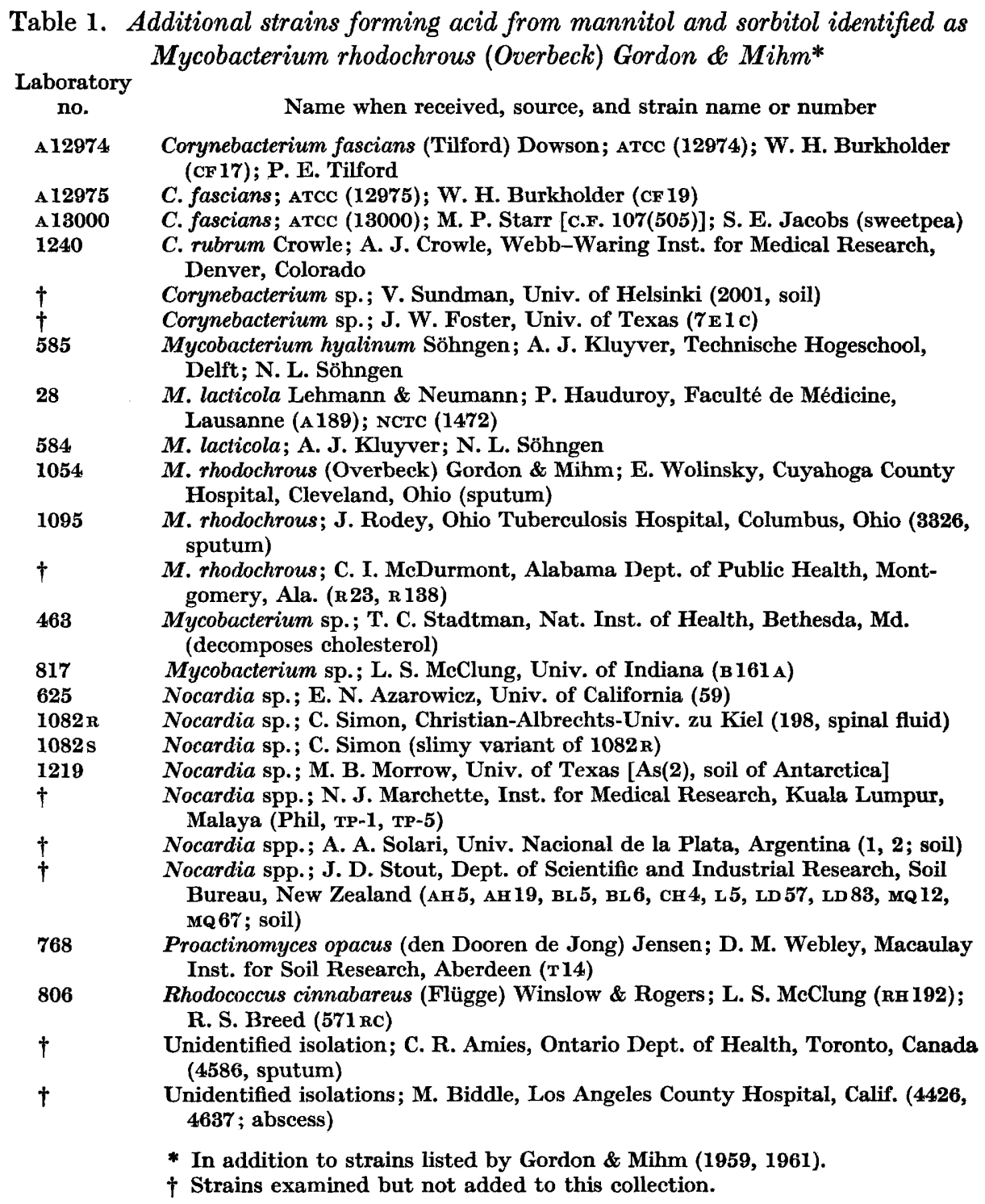

Some variation in the macroscopic appearance of the growth of strains tentatively labelled Mycobacterium rhodochrous is depicted in Pl. 1. Growth on 'yeast dextrose agar' was usually abundant and red, reddish orange, pink, yellow or beige in colour. The growth varied from raised, deeply wrinkled, dry and waxy, to flat, shiny, and smooth. A few cultures formed slimy growth that dripped on the cover of the 
inverted Petri dish during incubation. With continued cultivation on 'yeast dextrose agar', the red, orange, or pink pigment of some of the strains changed to yellow.

The 97 strains representing this species in our collection were Gram positive. After $18 \mathrm{hr}$ of incubation, $40 \%$ of the cultures were composed of branching filaments and rods, usually of varying lengths, or of branching filaments, rods, and coccoid forms; $37 \%$ of the cultures showed rods; and $23 \%$, rods and coccoid bodies. Only rods were formed by variants of three strains which produced branching filaments,

Table 2. Strains not forming acid from mannitol or sorbitol identified as Mycobacterium rhodochrous

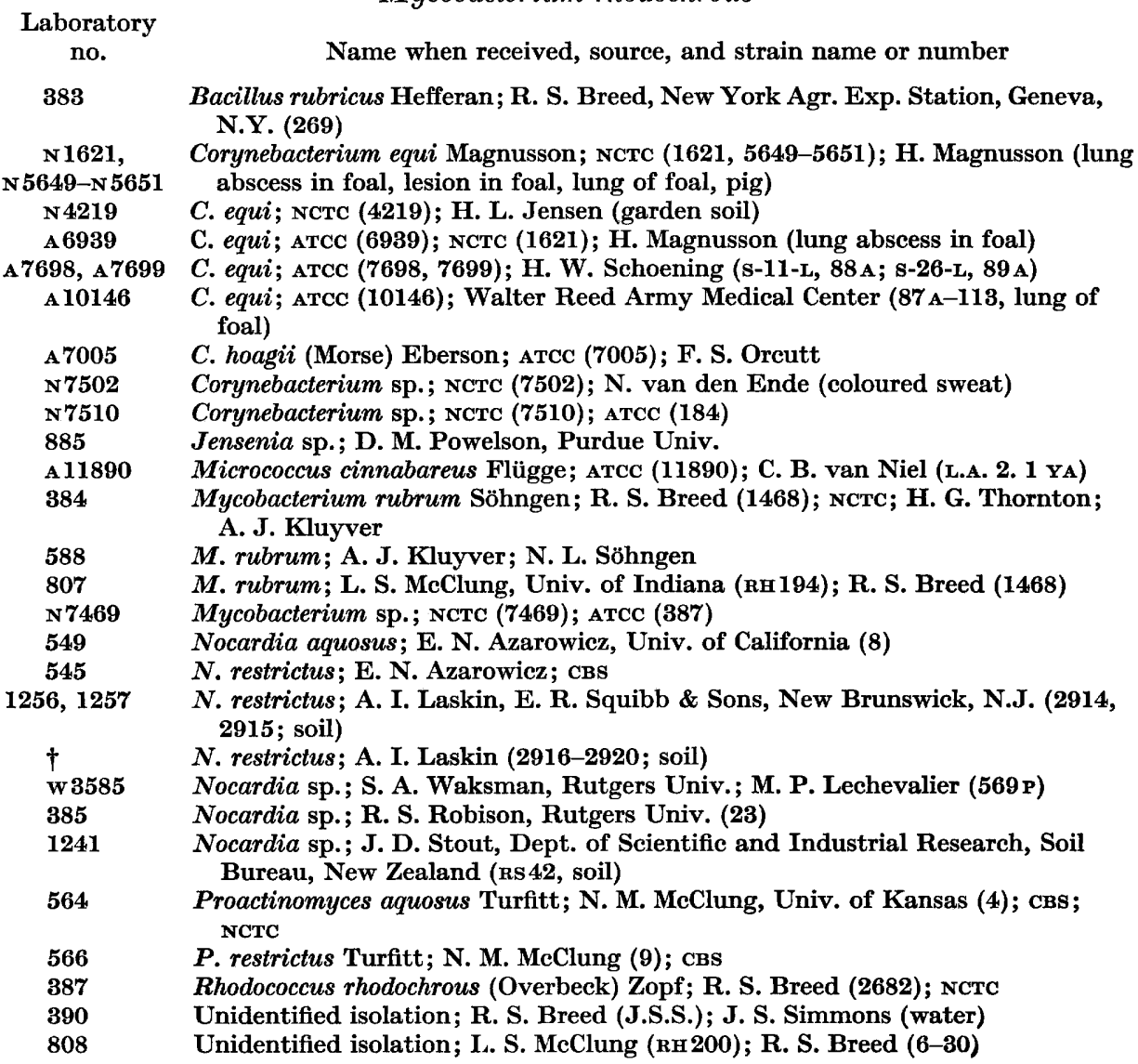
$\dagger$ Strains examined but not added to this collection.

and rods and coccoid bodies were exhibited by a variant of a strain which produced only rods. At 5 days, smears of $34 \%$ of the cultures contained only coccoid forms; smears of the remaining cultures contained rods and coccoid bodies.

Examination of the colonial morphology on Bennett's and soil extract agars disclosed that the colonies of $80(83 \%)$ of the 97 cultures tentatively named Mycobacterium rhodochrous were like the colonies of typical cultures of mycobacteria. Each of these 80 cultures exhibited dense colonies with smooth margins and one or both of the following types: (1) dense colonies with outcroppings or a halo of rods 
or filaments, and (2) filamentous colonies. The undisturbed filaments usually fragmented into short rods or coccoid bodies; aerial hyphae were not seen. Very thin colonies and medusa-head colonies were at times also present. Of the remaining $17 \%$ of the 97 cultures, $12 \%$ formed filamentous colonies and/or dense colonies with a fringe or outgrowths of rods or filaments (dense colonies with smooth edges were not observed), and $5 \%$ produced filamentous colonies with tufts or root-like

Table 3. Some physiological characteristics of Mycobacterium rhodochrous

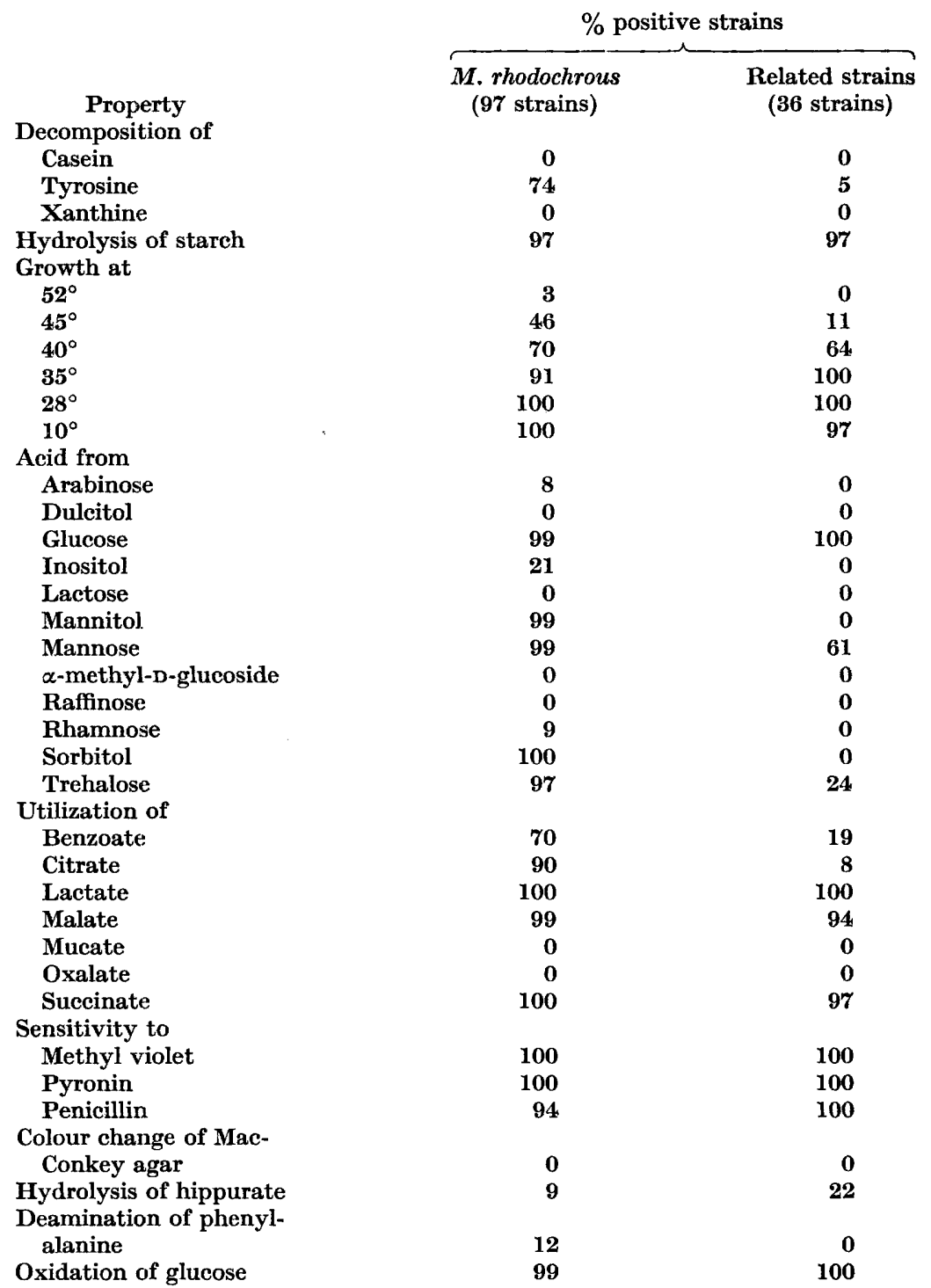

masses emerging from the central surface of the colony, resembling those shown by strain 1286 of $M$. fortuitum ( $\mathrm{Pl} .3$ ), and/or with short hyphae projecting into the air from the substrate hyphae at the margins of the colonies like those of strain 1286 
(Pl. 4). The projecting hyphae appeared to be no wider than the substrate hyphae. One of the cultures $(768 \mathrm{~A})$ forming short, projecting hyphae produced a variant $(768 \mathrm{~B})$ whose colonies were typical of the mycobacteria and were without hyphae extending into the air.

The results of the physiological tests applied to the 97 strains provisionally labelled Mycobacterium rhodochrous are given in Table 3. The more reliable physiological characteristics for identifying strains of this species were: failure to decompose casein and xanthine; hydrolysis of starch; lack of growth at $\mathbf{5 2}^{\circ}$; growth at

Table 4. Some disassociated characteristics of Mycobacterium rhodochrous

\begin{tabular}{|c|c|c|c|c|c|c|c|c|}
\hline \multirow[b]{2}{*}{ Strains } & \multicolumn{2}{|c|}{ Growth at } & \multicolumn{2}{|c|}{ Decomposition of } & \multicolumn{2}{|c|}{ Production of } & \multicolumn{2}{|c|}{ Acid from } \\
\hline & $45^{\circ}$ & $40^{\circ}$ & $\begin{array}{l}\text { Tyro- } \\
\text { sine }\end{array}$ & $\begin{array}{l}\text { Ben- } \\
\text { zoate }\end{array}$ & Nitrite & Urease & Inositol & Maltose \\
\hline $\begin{array}{c}\text { w21, w3406, } \\
371,729\end{array}$ & + & + & - & + & + & + & - & - \\
\hline $\begin{array}{l}\text { w3408, 363, } \\
364,366,367, \\
368,370,381, \\
452,1082 \mathrm{~s}, \\
\text { A4273, A4276 }\end{array}$ & + & + & + & + & + & + & - & - \\
\hline $\begin{array}{l}624,801,802 \\
805,806,809 \\
1082 \mathrm{R}, 12483\end{array}$ & + & + & + & + & + & + & - & + \\
\hline 502 & + & + & + & + & + & - & - & + \\
\hline $\begin{array}{l}\text { N576, 369, } \\
372,415,759\end{array}$ & + & + & + & + & + & - & - & - \\
\hline N 8139,462 & + & + & - & - & - & - & - & - \\
\hline 567 & + & + & + & + & + & - & + & - \\
\hline $\begin{array}{l}\text { w3639, 546, } \\
583,590,817\end{array}$ & - & + & + & + & + & - & - & - \\
\hline $382,482,839$ & - & + & - & + & + & + & - & - \\
\hline 28 & - & + & + & - & + & + & + & - \\
\hline 463 & - & + & + & - & - & + & + & - \\
\hline 386,388 & - & + & - & + & - & + & - & - \\
\hline 515 & - & + & - & - & + & + & - & + \\
\hline 620 & - & + & + & + & + & - & + & - \\
\hline N8154 & - & - & + & + & + & - & - & - \\
\hline 625,1219 & - & - & - & - & - & + & - & - \\
\hline 417,544, А9356 & - & - & + & + & + & + & - & - \\
\hline 587 & - & - & - & + & - & + & - & + \\
\hline $492,621,766$ & - & - & + & - & - & + & + & + \\
\hline N8036, 570, 584 & - & - & + & - & + & + & + & + \\
\hline
\end{tabular}

$28^{\circ}$ and at $10^{\circ}$; acid production from glucose, mannitol, mannose, sorbitol, and trehalose; inability to form acid from dulcitol, lactose, $\alpha$-methyl-D-glucoside, or raffinose; utilization of lactate, malate, and succinate; failure to use mucate or oxalate; sensitivity to methyl violet, pyronin, MacConkey agar, and penicillin; and the oxidative utilization of glucose. All but one ( $\mathrm{N6117}$ ) of the 97 cultures grew in the aerobic tube of Hugh \& Leifson's medium and changed the indicator to the acid colour; all but $\mathrm{N} 6117$ formed acid from glucose in aerobic culture on the medium of Ayers, Rupp \& Johnson (1919); and all cultures grew in the anaerobic tubes of both media but did not change the indicator to the acid colour.

Somewhat less dependable criteria for the recognition of strains of this species were: the decomposition of citrate and the inability (1) to form acid from arabinose 
or rhamnose, (2) to hydrolyse hippurate, or (3) to change phenylalanine to phenylpyruvic acid.

Some uncorrelated properties of the strains tentatively labelled Mycobacterium rhodochrous are presented in Table 4 . The strains are arranged in three groups: those growing at $45^{\circ}$, those growing at $40^{\circ}$ but not at $45^{\circ}$, and those unable to grow at $40^{\circ}$. The results of the remaining six tests included in Table 4 (decomposition of tyrosine, utilization of benzoate as a source of carbon, reduction of nitrate to nitrite, production of urease, and acid formation from inositol and maltose) were not associated with growth at $45^{\circ}$ or at $40^{\circ}$. The results of these eight tests, which were applied to all 97 strains of $M$. rhodochrous, did not correlate with each other or with any other of the properties examined. Some of these eight characteristics were not only variable for the species but also for the same strain. The slimy variant of strain 1082 formed acid from maltose while the $R$ variant did not. Strains A 4273, w 3408, and 502 (all Gray's strain 0-3) also differed in the production of acid from maltose. Strains w 3406, 370, and 624 (all Breed's strain KBMC) varied in the decomposition of tyrosine and formation of acid from maltose. Strains 584 and 587 (Söhngen's strain of $M$. luteum from Kluyver) differed in the decomposition of tyrosine, utilization of benzoate, reduction of nitrate to nitrite, and production of acid from inositol.

\section{Some strains closely related to Mycobacterium rhodochrous}

A group of strains considered closely related to those tentatively designated Mycobacterium rhodochrous is presented in Table 2. Because the nine strains received as Corynebacterium equi were believed to conform to Magnusson's (1924) original description of the species, and because five of the strains were deposited by Magnusson in the NCTC, the nine strains of $C$. equi were accepted as representatives of the species. The strains received as M. rubrum Söhngen (1913), Proactinomyces aquosus Turfitt (1944) and $\boldsymbol{P}$. restrictus Turfitt (1944) were also considered in agreement with the first accounts of their respective species. Authority for the assignment of $\boldsymbol{P}$. aquosus and $\boldsymbol{P}$. restrictus to the genus Nocardia was not found. Morse's (1912) description of Bacillus hoagii, repeated by Eberson (1918) in his transfer of this species to the genus Corynebacterium, is very meagre and of little assistance in establishing the authenticity of strain $\mathbf{A} 7005$.

Two strains (369 and 383) were received as Bacillus rubricus Hefferan (1904). Strain 369 was assigned to Mycobacterium rhodochrous by Gordon \& Mihm (1957); strain 383 is listed here in Table 2. Two strains (806 and A11890) labelled Micrococcus cinnabareus Flügge (1886) were mentioned earlier in this report under the heading M. rhodochrous. Two other strains (372 and 387) were obtained as Rhodococcus rhodochrous (Overbeck, 1891) Zopf (1891) from Breed as strains KMrh and 2682, respectively. Because strain 372 had the same pattern of reactions as strain w21 of Micrococcus rhodochrous, and because Breed (personal communication, 1954) vouched for the authenticity of his strain KMRh (372), Gordon \& Mihm (1957) accepted strain $\mathbf{3 7 2}$ as a representative of Overbeck's species. Strain 387 of $R$. rhodochrous is included in Table 2. The original accounts of the species B. rubricus and $\boldsymbol{R}$. rhodochrous, however, do not disprove the authenticity of any of these strains.

Some variation in the gross appearance of the cultures of this group is pictured in Pl. 2. On 'yeast dextrose agar', the growth was abundant and red, pink, pinkish orange, yellow, or beige. The cultures varied from raised, deeply wrinkled and waxy, 
to flat, smooth and shiny; a few cultures were slimy and dripped on the cover of the inverted Petri dish during incubation.

The 36 strains listed in Table 2 were Gram positive. After $18 \mathrm{hr}$ of incubation, $10 \%$ of the cultures contained filaments and rods, $32 \%$ showed rods, $45 \%$ showed rods and coccoid bodies, and $13 \%$ showed only coccoid forms. At 5 days, $29 \%$ of the cultures were composed of only coccoid bodies; the rest were a mixture of rods and coccoid forms.

The colonies of $89 \%$ of the 36 strains resembled those of typical cultures of mycobacteria and were dense, with smooth edges or with a fringe or outcroppings of filaments, and/or filamentous. The undisturbed filaments usually fragmented into rods or coccoid forms; aerial hyphae were not observed. One culture $(3 \%$ of the 36) produced filamentous colonies and dense colonies with a halo of filaments. The colonies of the remaining $8 \%$ of the cultures were filamentous, with root-like projections resembling those of strain 1286 of Mycobacterium fortuitum (Pl. 3) or with short hyphae arising from the substrate mycelia (Pl. 4).

A comparison of the physiological reactions of the 36 strains with the reactions of the 97 strains tentatively labelled Mycobacterium rhodochrous (Table 3) reveals that the two groups are separable only by acid formation from mannitol and sorbitol. Properties shared by these 36 strains were: failure to decompose casein, tyrosine, or xanthine; ability to hydrolyse starch; lack of growth at $52^{\circ}$; growth at $35^{\circ}, 28^{\circ}$, and $10^{\circ}$; formation of acid from glucose; inability to produce acid from arabinose, dulcitol, inositol, lactose, mannitol, $\alpha$-methyl-D-glucoside, raffinose, rhamnose, or sorbitol; utilization of lactate, malate, and succinate; sensitivity to dyes, MacConkey agar, and penicillin; inability to deaminate phenylalanine; and the oxidative utilization of glucose. All 36 cultures formed acid from glucose in aerobic culture on the inorganic nitrogen medium of Ayers et al. (1919) and all but one (1157) formed acid in the aerobic tube of Hugh \& Leifson's medium. All the cultures grew in the anaerobic tubes of both media but did not produce acid. A somewhat less dependable property of the $\mathbf{3 6}$ strains was their failure to use citrate.

\section{Comparison of four species of mycobacteria}

Cultures of the 40 strains of Mycobacterium phlei in this collection were Gram positive after $18 \mathrm{hr}$ at $35^{\circ}$ on 'yeast dextrose agar' and were composed of rods and an occasional filament. At 5 days, smears of all the cultures of $\boldsymbol{M}$. phlei contained coccoid forms, and $31 \%$ of the cultures exhibited only coccoid bodies.

The observations of the colonial morphology of the strains of Mycobacterium phlei, M. smegmatis, $\boldsymbol{M}$. fortuitum and $\boldsymbol{M}$. rhodochrous on Bennett's and soil extract agars are summarized in Table 5. Eighty-three to $89 \%$ of the strains of each of the four species formed dense, smooth colonies accompanied by dense colonies with a halo or outgrowths of rods or filaments and/or filamentous colonies. The filaments usually fragmented, and aerial hyphae were not demonstrated. All four species contained a much smaller percentage (4-12\%) of strains that exhibited dense colonies with a fringe or outcroppings of filaments and/or filamentous colonies but not dense, smooth colonies. Cultures of all four species (2-11\%) produced filamentous colonies with short, unbranched hyphae projecting upward from the substrate hyphae and/or colonies with tufts of hyphae extending from the central surface of the colonies (Pls. 3, 4). The short hyphae could be seen at the periphery of 
the colony and did not appear any wider than the substrate hyphae. The species containing the highest percentage of these atypical colonies (Pls. 3, 4) was $M$. fortuitum.

The results of three tests not applied previously (Gordon \& Mihm, 1959) to the strains of Mycobacterium phlei, M. smegmatis, and $M$. fortuitum in this collection are presented in Table 6 and compared with the reactions of strains tentatively

Table 5. Colonial morphology of four species of mycobacteria on Bennett's and soil extract agars

\begin{tabular}{|c|c|c|c|c|}
\hline \multirow[b]{2}{*}{ Species } & \multirow[b]{2}{*}{ No. of strains } & \multicolumn{3}{|c|}{$\begin{array}{l}\text { Distribution in colonial groups } \\
(\%)\end{array}$} \\
\hline & & $1 *$ & $2 \dagger$ & $3 \neq$ \\
\hline Mycobacterium phlei & 40 & 88 & 10 & $\mathbf{2}$ \\
\hline M. smegmatis & 95 & 89 & 4 & 7 \\
\hline M. fortuitum & 105 & 83 & 6 & 11 \\
\hline M. rhodochrous & 97 & 83 & 12 & 5 \\
\hline & 36 & 89 & 3 & 8 \\
\hline
\end{tabular}

* Dense colonies with smooth margins accompanied by dense colonies with halo or outcroppings of filaments and/or filamentous colonies.

$\dagger$ Same as colonies in group 1 without the dense, smooth colonies.

\$ Filamentous colonies with root-like masses and/or short hyphae projecting into the air.

Table 6. Comparison of three reactions of four species of mycobacteria

\begin{tabular}{|c|c|c|c|c|}
\hline \multirow[b]{2}{*}{ Property } & \multicolumn{4}{|c|}{$\%$ positive strains } \\
\hline & $\begin{array}{c}\text { M. phlei } \\
\text { (40 strains) }\end{array}$ & $\begin{array}{c}M . \text { smeg- } \\
\text { matis } \\
\text { (95 strains) }\end{array}$ & $\begin{array}{c}M . \text { for }- \\
\text { tuitum } \\
\text { (105 strains) }\end{array}$ & $\begin{array}{c}M . \text { rhodo- } \\
\text { chrous } \\
\text { (133 strains) }\end{array}$ \\
\hline dicillin & $\mathbf{0}$ & 0 & $\mathbf{0}$ & 95 \\
\hline hip & 98 & $\mathbf{0}$ & 94 & 7 \\
\hline of phenylalanine & 100 & 0 & $<1$ & 13 \\
\hline
\end{tabular}

designated $M$. rhodochrous. In contrast to the cultures of $M$. rhodochrous, cultures o $M$. phlei, $M$. smegmatis, and $M$. fortuitum were not inhibited by 10 units of penicillin. Although all the other strains of mycobacteria in this collection have not been tested for sensitivity to penicillin, $39 \%$ of the strains tested, which have retained their acid-fastness after many years of cultivation in vitro (including ATCC nos. 4234, 4235, 4239, 4241, and 4445), were sensitive to penicillin. Among 18 strains of Nocardia asteroides recently received for examination, 10 were resistant to penicillin. The correlation between acid-fastness and resistance to penicillin shown by $M$. phlei, $M$. smegmatis, $M$. fortuitum and $M$. rhodochrous was not confirmed by other strains of mycobacteria or of $N$. asteroides.

Strains of Mycobacterium phlei and of $M$. fortuitum hydrolysed hippurate, while strains of $M$. smegmatis did not. Strains of $M$. rhodochrous were usually negative. Phenylalanine was changed to phenylpyruvic acid by cultures of $M$. phlei, but not by cultures of $\boldsymbol{M}$. smegmatis or $\boldsymbol{M}$. fortuitum, and usually not by $\boldsymbol{M}$. rhodochrous. 


\section{DISCUSSION}

Among the criteria used in this comparative examination, only acid formation from mannitol and sorbitol separated the strains tentatively labelled Mycobacterium rhodochrous from the $\mathbf{3 6}$ strains listed in Table 2. Future investigations may, of course, provide other tests and observations that would correlate with acid production from mannitol and sorbitol. At present, however, although the reactions on only two carbohydrates are possibly enough for varietal distinction, they are not considered sufficient evidence for the separation of species; the strains presented in Tables 1 and 2 and listed by Gordon \& Mihm $(1959,1961)$ are thus believed to belong to one species, provisionally designated $M$. rhodochrous.

The generic assignment of this species presents a difficult problem. Cummins (1962) reported that strains of Mycobacterium cinnabareus, $\boldsymbol{M}$. rhodochrous, Corynebacterium fascians and $C$. equi had the same major constituents in their cell walls as strains of other Mycobacterium species, C. diphtheriae and Nocardia asteroides. Becker, Lechevalier \& Lechevalier (1965) also found that a strain of $M$. rhodochrous (502 received as ATCC strain 4273 of $N$. corallina) had the same cell-wall composition as strains of $N$. asteroides. Although the cell-wall constituents of only a relatively few strains have been determined, the data accumulated thus far would support an assignment of this species, tentatively named $M$. rhodochrous, to the genus Corynebacterium, Mycobacterium, or Nocardia.

The finding that strains of Corynebacterium fascians and $C$. rubrum had the same morphological and physiological properties as strains provisionally named Mycobacterium rhodochrous, and that strains of $C$. equi and $C$. hoagii shared the same characteristics except for the production of acid from mannitol and sorbitol, suggested the assignment of the species 'rhodochrous' to the genus Corynebacterium. This generic assignment is prevented, for the present at least, by the ability of these strains to utilize glucose oxidatively. According to Cowan \& Steel (1965), the corynebacteria of medical importance ferment or do not attack glucose by the Hugh \& [Leifson test; strains of $C$. diphtheriae, the type species, ferment glucose. Carrier (1964), Conn \& Dimmick (1947), Lacey (1955), and others, who compared strains of various other species of Corynebacterium, questioned the location of the plant pathogenic species fascians in the genus Corynebacterium. Although the exclusion of strains that oxidize glucose from the genus Corynebacterium has not been suggested, such an exclusion might prove very useful in the delineation of the genus. A proposal that the glucose-oxidizing species tentatively labelled M. rhodochrous (which includes strains of $C$. fascians) should be placed in the genus Corynebacterium does not, therefore, seem feasible at this time.

The placement of this species in the genus Nocardia in accord with Bergey's Manual of Determinative Bacteriology (1957), with McClung \& Adams (1962), and with many others, is opposed here because of a belief that the genus Nocardia should be limited to strains like those of the type species, $N$. asteroides ( $N$. farcinica), which form filamentous colonies and aerial hyphae visible to the unaided eye. Although strains of $N$. asteroides may lose the ability to form aerial hyphae abundantly, their cultivation on a variety of media, such as those used in the series of tests applied here, usually produces cultures with aerial hyphae that are visible macroscopically as well as microscopically. 
The genus Nocardia is currently a catch-all. It contains strains which, in my opinion, are morphologically quite different from those of the type species; for example, motile strains ( $N$. turbata Erikson, 1954) and slime-forming strains like 1157 , received as $N$. restrictus (Pl. 2, figs. 8, 9), and like $1082 \mathrm{~s}$, received as Nocardia sp. (Pl. 1, figs. 5, 6). Strain $1082 \mathrm{~s}$ is a variant of strain $1082 \mathrm{R}$ (Pl. 1, fig. 4), which has the same appearance, morphology, and physiological properties as, for example, strain 370 ( $\mathrm{Pl} .1$, fig. 2), received as $N$. corallina.

Lacey (1955) pointed out the morphological similarity between strains of $M \mathrm{yco}^{-}$ bacterium phlei and Corynebacterium fascians and their likeness to cultures of Nocardia spp. as illustrated by McClung (1950). Lacey's observations are confirmed in this report. The appearance of coccoid forms in cultures of mycobacteria, described by other investigators, was recently reviewed by Csillag (1964). The unreliability of the formation of branching filaments for separating strains of mycobacteria and nocardiae is well demonstrated by Cuttino \& McCabe's (1949) delineation of Nocardia intracellularis, which Runyon (1965) reported to be the same as the Battey strains of mycobacteria.

The lack or low degree of acid-fastness by strains tentatively designated $M \mathrm{Mco}^{-}$ bacterium rhodochrous is, I believe, the main objection to their assignment in the genus Mycobacterium. The amount of acid-fastness of strains belonging to some species generally accepted in the genus Mycobacterium, however, is not uniform; for example, only $10-20 \%$ of the rods in smears of some cultures of $M$. phlei and of $M$. smegmatis retained the carbol fuchsin after being dipped once in acid alcohol and quickly rinsed in water (Gordon \& Smith, 1953). Lacey (1955) found that cultures of Corynebacterium fascians and $C$. equi exhibited acid-fastness when grown on special media, and some strains tentatively labelled $M$. rhodochrous were known to be acid-fast when first isolated (Gordon \& Mihm, 1959). Nevertheless, the acidfastness of these strains was a variable characteristic, and the lipids of a few strains of $M$. rhodochrous, according to Lanéelle, Asselineau \& Castelnuovo (1965), were chemically like those of Nocardia asteroides rather than like the lipids of two strains of mycobacteria.

The assignment of strains belonging to the species 'rhodochrous' to 11 different genera by different investigators is proof of the generically intermediate nature of the species and causes speculation concerning the presence of strains having the same morphology and distinguishing pattern of reactions in still other genera, for example Arthrobacter and Brevibacterium. A proposal of any generic assignment of this wandering species should be made only on the basis of further study and on the establishment of clearer delineations of the genera Corynebacterium, Mycobacterium, Nocardia, and other closely related genera such as Arthrobacter.

This study was supported in part by research grant GB-2579 from the National Science Foundation, Washington, D.C., U.S.A. The author is grateful for this assistance and for that of Dr H. A. Lechevalier, Rutgers University, who provided the photographs; of Miss Shirley M. McMillen, Hektoen Institute, who suggested the penicillin test; and of Ciba Pharmaceutical Products, Inc., Schering Corporation, and Warner-Lambert Research Institute, who shared the cost of the colour plates. 


\section{REFERENCES}

Ayers, S. H. \& RuPP, P. (1922). Differentiation of hemolytic streptococci from human and bovine sources by the hydrolysis of sodium hippurate. J. infect. Dis. 30, 388.

Ayers, S. H., Rupp, P. \& Jornson, Jun., W. T. (1919). A study of the alkali-forming bacteria found in milk. Bull. U.S. Dept. Agr. no. 782.

Baird-Parker, A. C. (1963). A classification of micrococci and staphylococci based on physiological and biochemical tests. J. gen. Microbiol. 30, 409.

Becker, B., Lechevalier, M. P. \& Lechevalier, H. A. (1965). Chemical composition of cell-wall preparations from strains of various form-genera of aerobic actinomycetes. Appl. Microbiol. 13, 236.

Bergey's Manual of Determinative Bacteriology (1957). 7th ed., p. 713. Ed. R. S. Breed, E. G. D. Murray and N. R. Smith. Baltimore: Williams and Wilkins.

Carrier, E. B. (1964). Atypical species of Corynebacterium. Bact. Proc. p. 22.

ConN, H. J. \& Dimmick, I. (1947). Soil bacteria similar in morphology to Mycobacterium and Corynebacterium. J. Bact. 54, 291.

Cowan, S. T. \& Steel, K. J. (1965). Manual for the Identification of Medical Bacteria. Cambridge University Press.

Crowle, A. J. (1962). Corynebacterium rubrum nov.spec. a Gram-positive nonacid-fast bacterium of unusually high lipid content. Antonie van Leeurvenhoek, 28, 182.

Csillag, A. (1964). The mycoccus form of mycobacteria. J. gen. Microbiol. 34, 341.

Cummins, C. S. (1962). Chemical composition and antigenic structure of cell walls of Corynebacterium, Mycobacterium, Nocardia, Actinomyces and Arthrobacter. J. gen. Microbiol. 28, 35.

Cutrino, J. T. \& MCCABE, A. M. (1949). Pure granulomatous nocardiosis: a new fungus disease distinguished by intracellular parasitism. Am. J. Path. 25, 1.

Dowson, W. J. (1941). On the generic name of the Gram-positive bacterial plant pathogens. Trans. Br. mycol. Soc. 25, 311.

Eberson, F. (1918). A bacteriologic study of the diphtheroid organisms with special reference to Hodgkin's disease. J. infect. Dis. 23, 1.

Erikson, D. (1954). Factors promoting cell division in a 'soft' mycelial type of Nocardia: Nocardia turbata n.sp. J. gen. Microbiol. 11, 198.

Ewing, W. H., Davis, B. R. \& Reavis, R. W. (1957). Phenylalanine and malonate media and their use in enteric bacteriology. Public Health Lab. 15, 153.

FlügGe, C. (1886). Die Mikroorganismen, 2 Aufl., p. 174. Leipzig: F. C. W. Vogel.

Gondon, R. E. \& Minm, J. M. (1957). A comparative study of some strains received as nocardiae. J. Bact. 73, 15.

Gordon, R. E. \& Minm, J. M. (1959). A comparison of four species of mycobacteria. J. gen. Microbiol. 21, 736.

Gordon, R. E. \& Minm, J. M. (1961). The specific identity of Jensenia canicruria. Can. J. Microbiol. 7, 108.

Gordon, R. E. \& Smith, M. M. (1953). Rapidly growing, acid fast bacteria. I. Species' descriptions of Mycobacterium phlei Lehmann and Neumann and Mycobacterium smegmatis (Trevisan) Lehmann and Neumann. J. Bact. 66, 41.

Hefferan, M. (1904). A comparative and experimental study of bacilli producing red pigment. Zentbl. Bakt.ParasitKde (Abt. 2), 11, 397.

Hugh, R. \& Leifson, E. (1953). The taxonomic significance of fermentative versus oxidative metabolism of carbohydrates by various Gram negative bacteria. J. Bact. 66,24.

International Code of Nomenclature of Bacteria and Viruses. (1958). Ed. Editorial Board of the International Committee on Bacteriological Nomenclature. Ames: Iowa State College Press.

LACEY, M. S. (1955). The cytology and relationships of Corynebacterium fascians. Trans. Br. mycol. Soc. 38, 49.

lanéelle, M. -A., Asselineau, J. \& Castelnuovo, G. (1965). Études sur les mycobactéries et les nocardiae. IV. Composition des lipides de Mycobacterium rhodochrous, $M$. pellegrino sp., et de quelques souches de nocardiae. Annls Inst. Pasteur, Paris, 108, 69. 
Lehmann, K. B. \& Neumann, R. O. (1899). Bakteriologische Diagnostik, 2, 408. München: L. F. Lehmann.

McClung, N. M. (1950). Morphological studies in the genus Nocardia. II. Cytological studies. J. Bact. 59, 589.

McClung, N. M. \& Adams, J. N. (1962). The morphology of actinomycetes in the genus Nocardia. Revta lat.-am. Microbiol. (suppl. 9) 5, 1.

Magnusson, H. (1924). Spezifische infektiöse Pneumonie beim Fohlen. Ein neuer Eitererreger beim Pferde. Arch. wiss. prakt. Tierheilk. 50, 22.

Morse, M. E. (1912). A study of the diphtheria group of organisms by the biometrical method. J. infect. Dis. 11, 253.

Overbeck, A. (1891). Zur Kenntnis der Fettfarbstoff-Production bei Spaltpilzen. Nova Acta Leopoldina, 55, 399.

Runyon, E. H. (1965). Pathogenic mycobacteria. Advanc. tuberc. Res. 14, 235.

Söhngen, N. L. (1913). Benzin, Petroleum, Paraffinöl und Paraffin als Kohlenstoff und Energiequelle für Mikroben. Zentbl. Bakt.ParasitKde (Abt. 2), 37, 595.

Tilford, P. E. (1936). Fasciation of sweet peas caused by Phytomonas fascians n.sp. J. Agric. Res. 53, 383.

TurfitT, G. E. (1944). Microbiological agencies in the degradation of steroids. I. The cholesterol-decomposing organisms of soils. J. Bact. 47, 487 .

Waksman, S. A. (1950). The actinomycetes. Annls cryptog. phytopath. 9, 196.

Winslow, C.-E. A. \& Rogers, A. F. (1906). A statistical study of generic characters in the Coccaceae. J. infect. Dis. 3, 485.

ZopF, W. (1891). Über Ausscheidung von Fettfarbstoffen (Lipochromen) seitens gewisser Spaltpilze. Ber. dt. bot. Ges. 9, 22.

\section{EXPLANATION OF PLATES}

Growth of cultures of Mycobacterium rhodochrous on 'yeast dextrose agar' after 10 days of incubation at $28^{\circ}$ (Pls 1 and 2).

\section{Plate 1}

Fig. 1. Strain 1240, received as Corynebacterium rubrum.

Fig. 2. Strain 370, received as Serratia corallina.

Fig. 3. Strain w 3406, received as Nocardia corallina.

Fig. 4. Strain $1082 \mathrm{R}$, received as Nocardia sp.

Fig. 5. Strain $1082 \mathrm{~s}$, slimy variant of strain $1082 \mathrm{R}$.

Fig. 6. Slime accumulated on cover of Petri dish beneath culture 1082s during incubation.

Fig. 7. Strain 674, received as Nocardia sp., growth from culture lyophilized in 1956.

Fig. 8. Strain 674, from culture maintained in vitro since 1955 .

Fig. 9. Strain 625, received as Nocardia sp.

Plate 2

Fig. 1. Strain 390, received as an unidentified isolation.

Fig. 2. Strain N7502, received as Corynebacterium sp.

Fig. 3. Strain 588, received as Mycobacterium rubrum.

Fig. 4. Strain N1621, received as C. equi.

Fig. 5. Strain 885, received as Jensenia sp.

Fig. 6. Strain w 3585 , received as Nocardia sp.

Fig. 7. Strain 549, received as $N$. aquosus.

Fig. 8. Strain 1257, received as $N$. restrictus.

Fig. 9. Slime accumulated on cover of Petri dish beneath culture 1257 during incubation. 

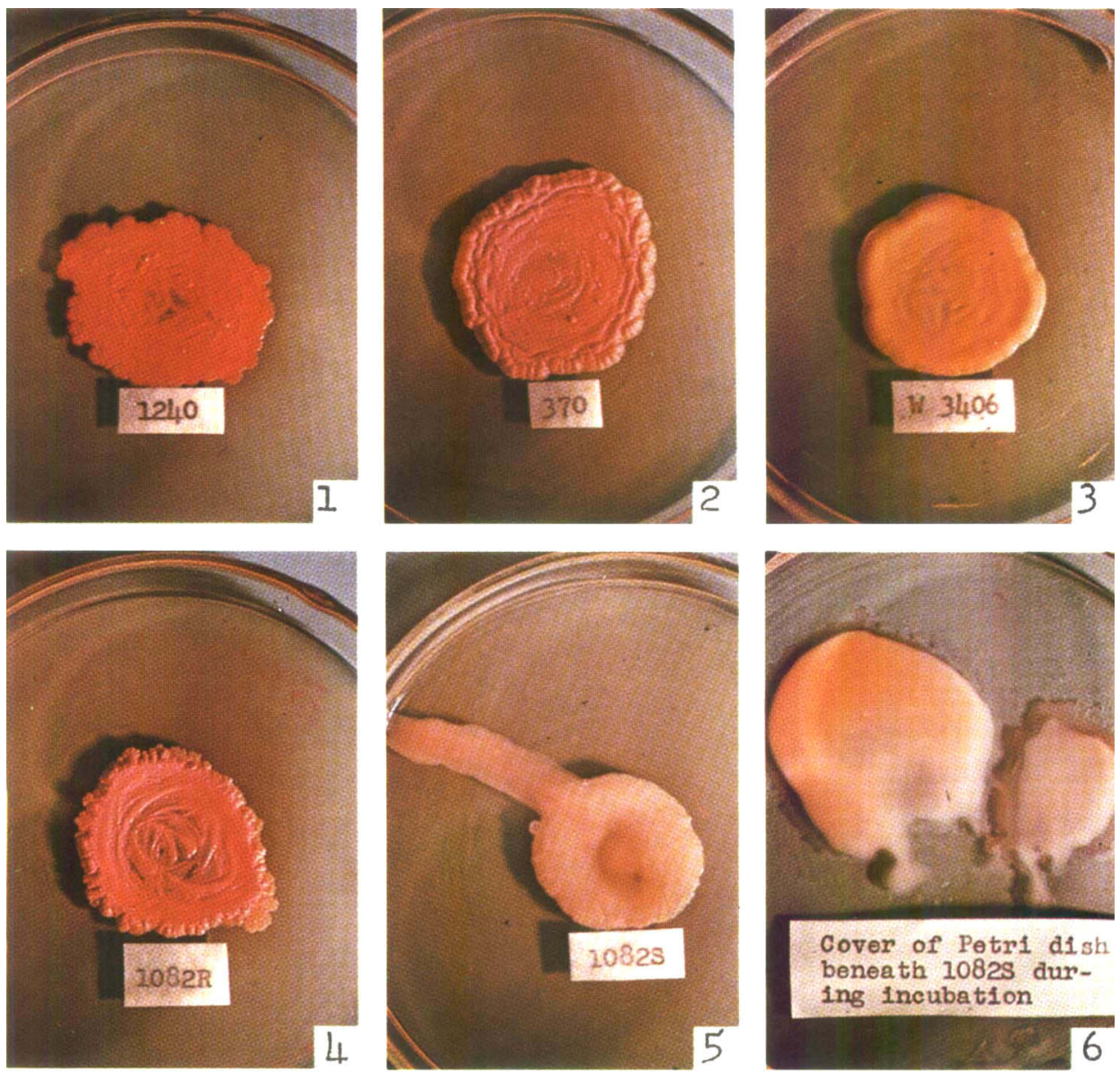

Cover of Petri dish beneath $1082 S$ during incubation
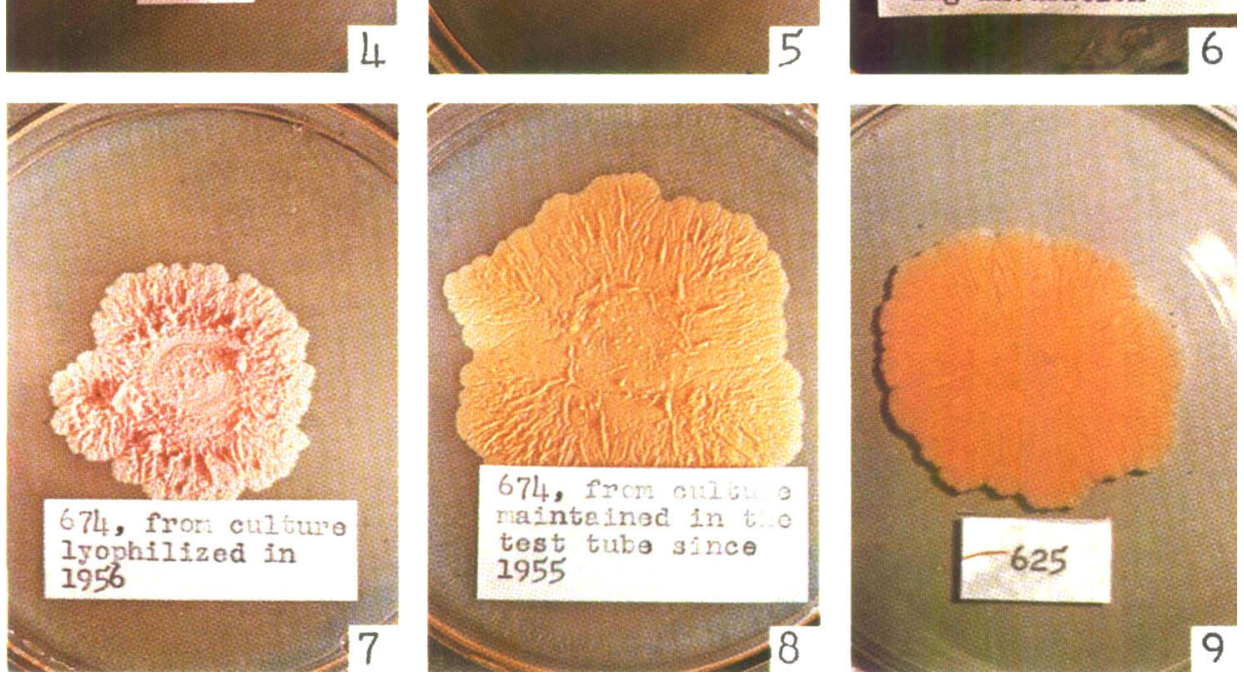

R. E. GORDON

(Facing $p .342$ ) 
Journal of General Microbiology, Vol. 43, No. 3

PLATE 2
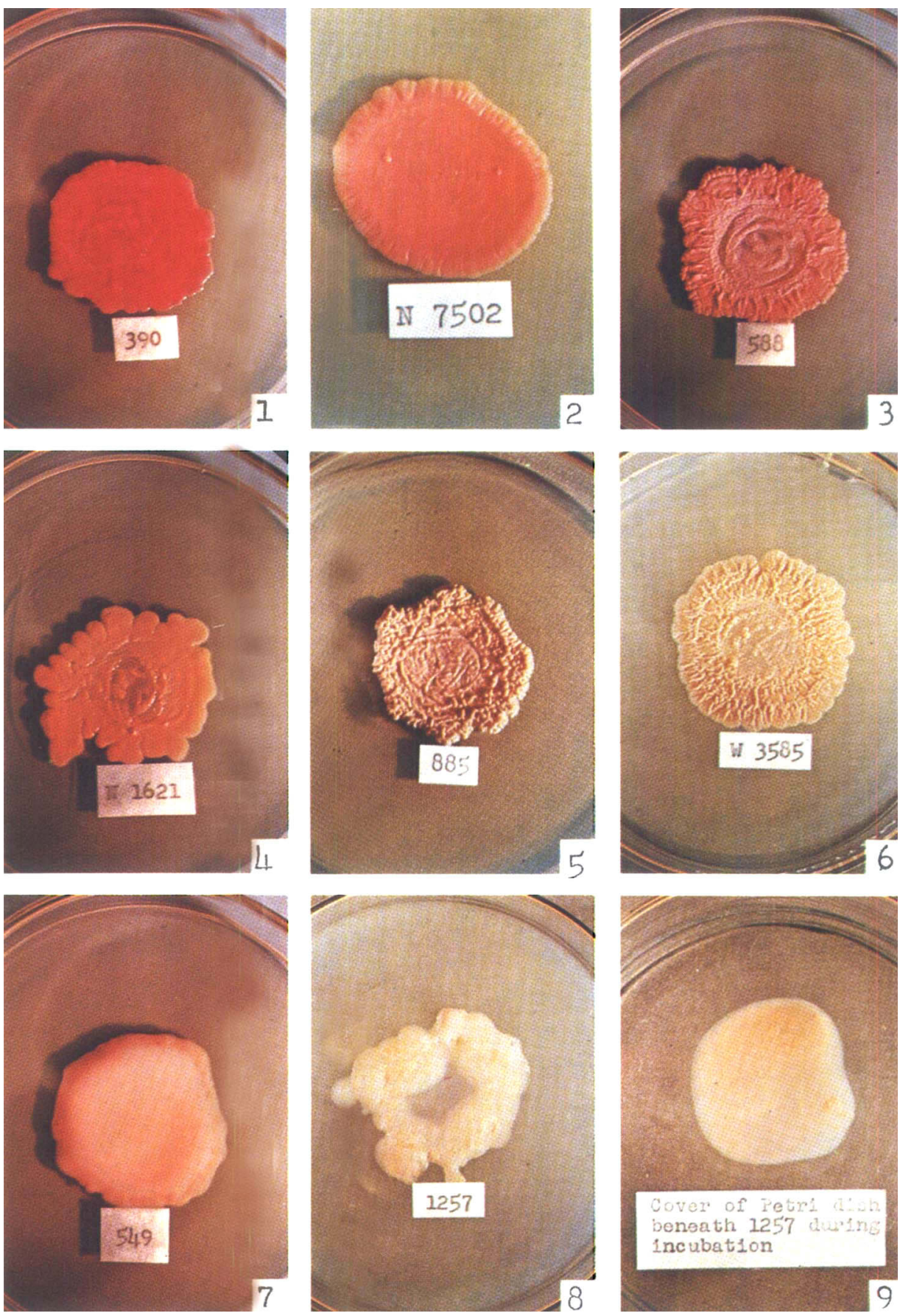

R. E. GORDON 
Journal of General Microbiology, Vol. 43, No. 3

Plate 3
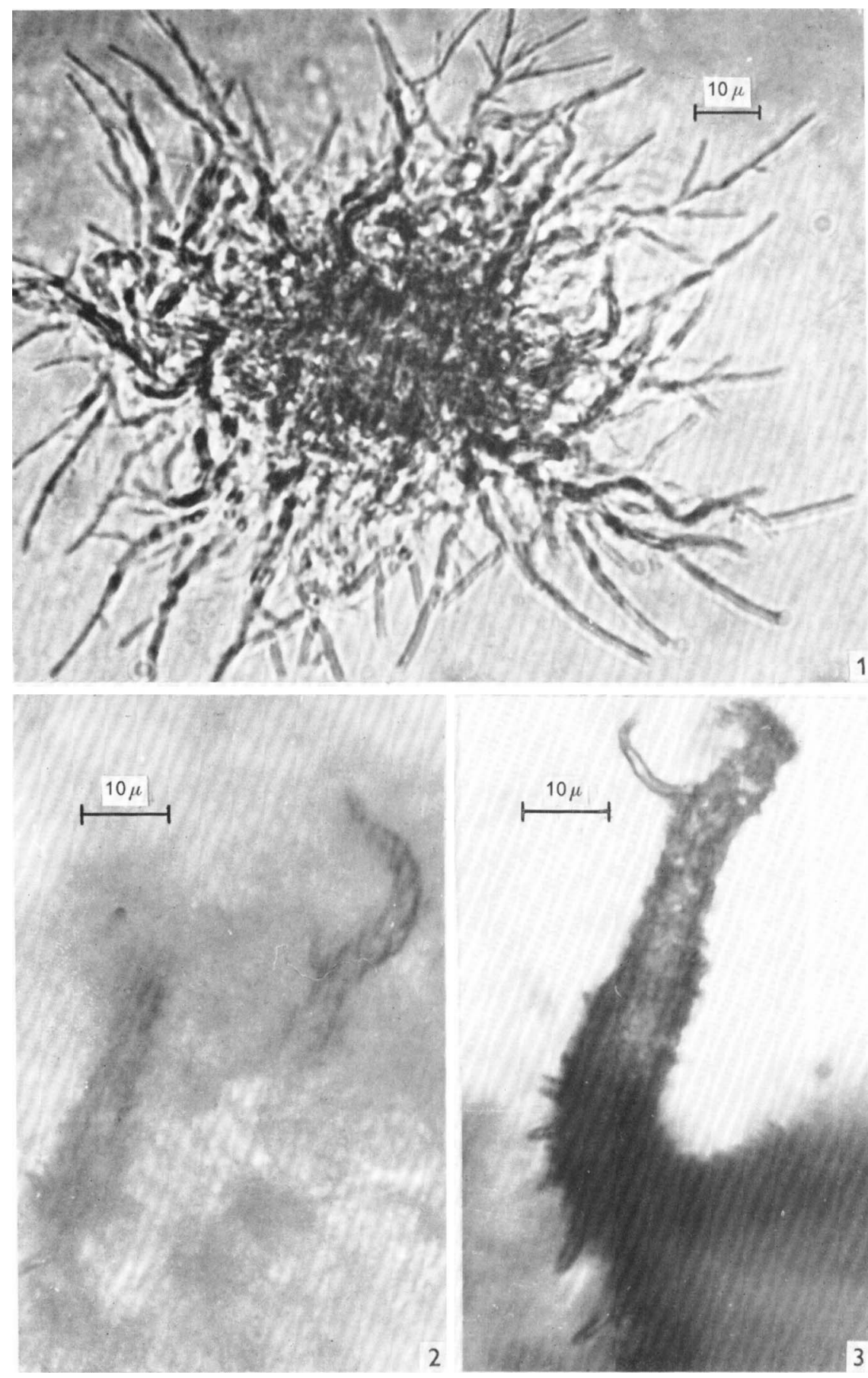

R. E. GORDON 

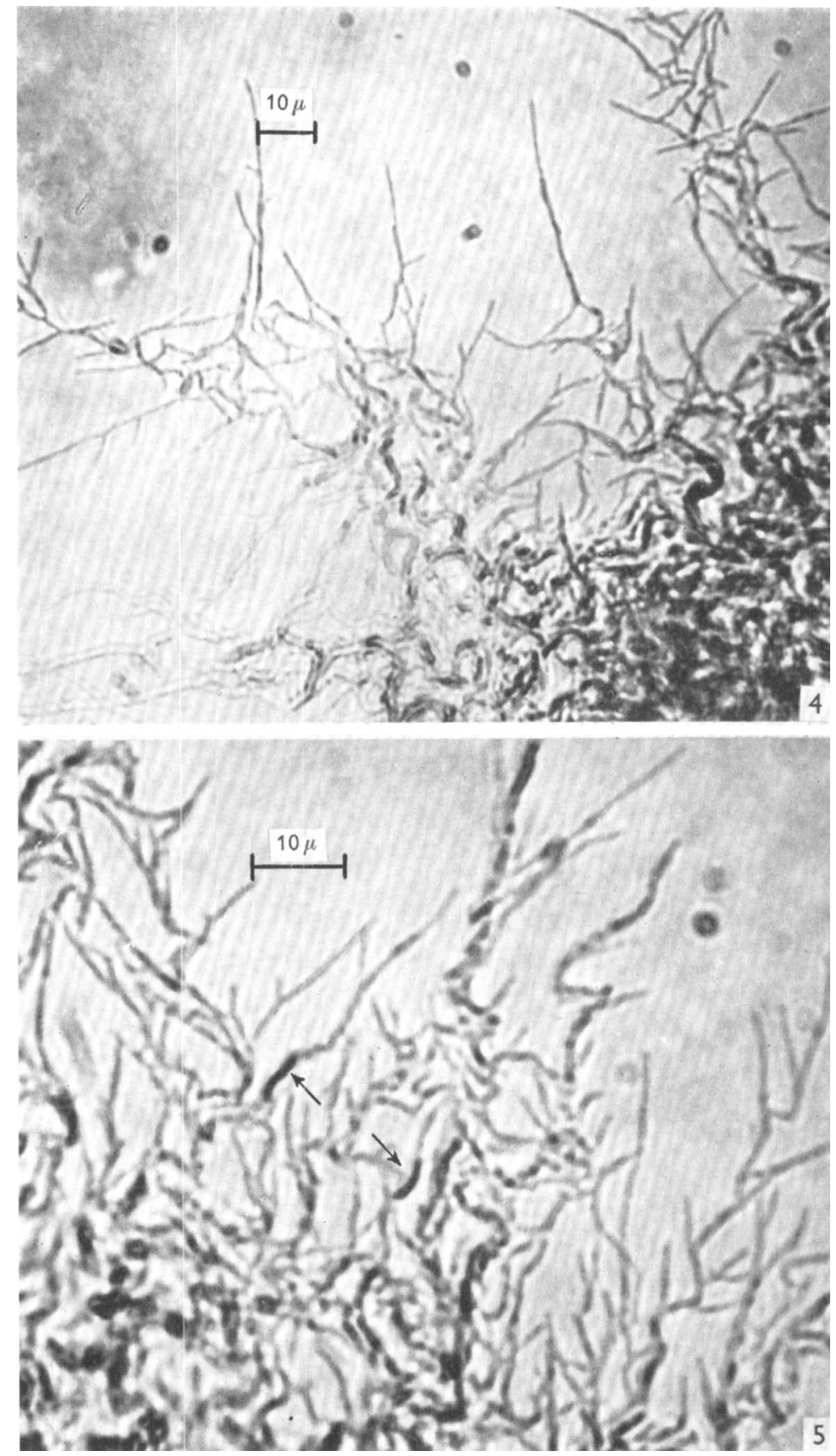

R. E. GORDON 
Microscopic appearance of colonies of strain 1286 of Mycobacterium fortuitum (Pls 3 and 4).

\section{Plate 3}

Fig. 1. Colony on soil extract agar at 3 days.

Figs. 2, 3. Tufts of hyphae projecting from centre of colony on Bennett's agar at 7 days.

Plate 4

Fig. 4. Substrate hyphae at margin of colony on soil extract agar at 7 days.

Fig. 5. Substrate hyphae with short hyphae projecting into the air, on soil extract agar at_7 days. 